\title{
Reseña de Sentencias del Tribunal Constitucional sobre la Administración Local y Autonómica que aparecen publicadas en el BOE durante el segundo semestre de 1997
}

\author{
Francisco Javier Fernández González \\ Profesor Titular de Derecho Administrativo \\ Universidad de Oviedo
}

Sumario: I. FUENTES. RECURSO DE INCONSTITUCIONALIDAD. II. JURISDICCIÓN CONTENCIOSO-ADMINISTRATIVA. III. DERECHO PÚBLICO DE LA ECONOMÍA: A) Mercado de Valores. B) Seguros. Planes y Fondos de Pensiones. IV. ENSEÑANZA. V. PROPIEDAD INTELECTUAL.

\section{FUENTES. RECURSO DE INCONSTITUCIONALIDAD}

1. Recursos de inconstitucionalidad acumulados núms. 256 y 264/1988, promovidos, respectivamente, por el Consejo Ejecutivo de la Generalidad de Cataluña y por el Gobierno Vasco, en relación con diversos preceptos de la Ley 22/1987, de 11 de noviembre, de Propiedad Intelectual. Estimación parcial de los recursos. El TC señala que si bien en el ámbito de los recursos de inconstitucionalidad la regla general es que la derogación de la norma extingue el objeto del recurso, no obstante constituyen una excepción a esta regla general los supuestos en los que existe una controversia competencial entre el Estado y las Comunidades Autónomas o de éstas entre sí. Asimismo indica el TC que en este caso al no estar recurrido como tal el texto refundido, el enjuiciamiento de los preceptos de la Ley permite trasladar sus efectos a su reproducción en el texto refundido.

«Según reiterada doctrina constitucional, no cabe dar una respuesta unívoca y general a la cuestión relativa a los efectos de la modificación, derogación o pérdida de vigencia de una disposición legal, ulterior a su impugnación, sobre la eventual desaparición del objeto de los diversos procesos constitucionales, la cual ha de venir determinada "en función de la incidencia real de la modificación o derogación, no decriterios abstractos" (STC 385/1993, f.j. 2).

En el ámbito del recurso de inconstitucionalidad, recurso abstracto y orientado a la depuración objetiva del ordenamiento, la pérdida sobrevenida de la 
vigencia del precepto legal impugnado "habrá de ser tenida en cuenta por este Tribunal para apreciar si la misma conlleva ... la exclusión de toda la aplicabilidad de la Ley (pues) si así fuera, no habría sino que reconocer que desapareció, al acabar su vigencia, el objeto de este proceso constitucional que, por sus notas de abstracción y objetividad, no puede hallar su exclusivo sentido en la eventual remoción de las situaciones jurídicas creadas en aplicación de la Ley,acaso inconstitucional (art. 40.1 LOTC)" (STC 199/1987, f.j. 3. ${ }^{\circ}$ ). Por ello, carece de sentido, tratándose de un recurso de inconstitucionalidad, "pronunciarse sobre normas que el mismo legislador ha expulsado ya de dicho ordenamiento ... de modo total, sin ultraactividad" (SSTC 160/1987, f.j. 6; 150/1990, f.j. 8; 385/1993, f.j. 2). Por idéntica razón, para excluir "toda aplicación posterior de la disposición legal controvertida, privándola así del vestigio de vigencia que pudiera conservar", puede resultar útil —conveniente- su enjuiciamiento, aun cuando haya sido derogada (SSTC 160/1987, f.j. 6; 385/1993, f.j. 2). La regla general en el ámbito de los recursos de inconstitucionalidad es, pues, que la derogación extingue su objeto.

No obstante, constituyen una excepción a esta regla general aquellos supuestos en los que a través de un recurso de inconstitucionalidad lo que se traba en realidad es una controversia sobre el ámbito de las competencias respectivas del Estado y de las Comunidades Autónomas o de éstas entre sí, de modo que lo que debiera ser objeto propio de un conflicto positivo de competencias como cauce procesal específico, ha de configurarse como fundamento de una pretensión de inconstitucionalidad por razón del rango legal de la norma controvertida. Desde tal perspectiva ha de contemplarse también en estos casos la incidencia de la derogación sobrevenida de la disposición legal impugnada sobre una eventual desaparición del objeto del proceso, en los que resulta aplicable, como ya hemos declarado en la STC 182/1992 (f.j. 1) y reiterado posteriormente en las SSTC 385/1993 (f.j. 2), 43/1996 (f.j. 3) y 61/1997 (f.j. 3), el criterio sostenido en relación a los conflictos positivos de competencia, ofreciendo aquella incidencia en este tipo de procesos matices peculiares como pone de manifiesto un somero repaso de la doctrina constitucional recaída al respecto.

De acuerdo con la mencionada doctrina constitucional, es cierto que "si la norma objeto de un conflicto es derogada por otra posterior puede provocarse sobrevenidamente la pérdida del objeto del conflicto mismo y, en consecuencia, resultar improcedente que éste sea resuelto mediante sentencia" (STC $248 / 1988$, f.j. 2), pero hay que huir de todo automatismo en los efectos que en los procesos conflictuales quepa conceder a las modificaciones o derogaciones sobrevenidas de las disposiciones discutidas, puesto que no basta con el mero agotamiento de la disposición o resolución impugnada o con su derogación o modificación para concluir si se requiere una decisión sobre el fondo (SSTC 147/1991, f.j. 9; 202/1992; 133/1993; 158/1992, f.j. 1), y hay que estar sustan- 
cialmente a la persistencia o no de la controversia competencial (STC 182/1988, f.j. 1), con el fin de salvaguardar el principio de la irrenunciabilidad o indisponibilidad de las competencias por las partes y, al tiempo, custodiar la vigencia de las normas constitucionales y estatutarias atributivas de competencias (STC 329/1993, f.j. 1).

Como este Tribunal ha tenido oportunidad de afirmar en numerosas resoluciones, sólo está llamado a pronunciarse sobre la titularidad de una competencia en la medida en que se trate de una competencia controvertida o de que la disputa esté todavía viva, debiendo inevitablemente resolver los términos de un conflicto mientras la esfera respectiva de competencias no resulte pacífica y aunque la disposición sobre la que se trabó el conflicto resulte luego derogada o modificada. En definitiva, la función de preservar los ámbitos respectivos de competencias no puede quedar enervada por la sola derogación o modificación de las disposiciones cuya adopción dio lugar al litigio, cuando aquella preservación exige aún, porque así lo demandan las partes, o al menos una de ellas, una decisión jurisdiccional que declare, constatando si se verificó o no la extralimitación competencial denunciada, su definición constitucional o estatutaria (SSTC 182/1988, f.j. 1; 248/1988, f.j. 2; 167/1993, f.j. 2; 329/1993, f.j. 1; 165/1994. f.j. 2).

Con arreglo a esta doctrina hemos de enjuiciar la controversia competencial planteada en los presentes recursos respecto de la LPI, sin que el hecho de su derogación por el texto refundido - que no ha sido recurrido- en cuanto reproduce los preceptos impugnados, represente obstáculo alguno para su enjuiciamiento. No altera esta conclusión, basada en la doctrina que ha quedado expuesta, la reciente STC 61/1997, de 20 de marzo, resolutoria de diversos recursos de inconstitucionalidad, acumulados, interpuestos unos contra la Ley 8/1990, sobre Reforma del Régimen Urbanístico y Valoración del Suelo, y otros frente al Texto Refundido de la Ley sobre el Régimen del Suelo y Ordenación Urbana, aprobado por el Real Decreto Legislativo 1/1992, de 26 de junio, pues si bien en el fundamento jurídico tercero de esta sentencia, después de reiterar la aplicación a los recursos de inconstitucionalidadde carácter conflictual la doctrina expuesta en orden a los conflictos de competencias, llega a la conclusión de que en el caso por ella resuelto, al tener por objeto los recursos acumulados en unos casos la Ley 8/1990 y en otros el texto refundido, no había necesidad de examinar los ámbitos competenciales debatidos desde el ángulo de aquella Ley, puesto que "se halla derogada precisamente en la misma medida en que es sustituida por el TRLS, que como tal texto refundido, carece técnicamente de capacidad innovadora, con lo que la controversia competencial puede trasladarse, prácticamente en sus propios términos, a sus disposiciones, como así ha ocurrido efectivamente". Y es precisamente por esa falta de necesidad y no por ninguna otra razón, por lo que en la STC 61/1997 no se estima- 
ron subsistentes los recursos interpuestos frente a la Ley $8 / 1990$, toda vez que la cuestión en ellos planteada "será satisfecha al analizar, desde la perspectiva constitucional, la norma que la ha sustituido y que, a la vez, al enjuiciar las impugnaciones relativas al TRLS se resolverán las cuestiones en torno a la Ley delegada".

Es, pues, claro que la pérdida de objeto de los recursos interpuestos contra la Ley 8/1990 declarada por la STC 61/1997, se produjo exclusivamente por resultar innecesario su examen, pero de ella se desprende con claridad que, de no darse la circunstancia de la acumulación de aquellos recursos a los planteados frente al texto refundido, la controversia competencial no hubiera perdido su objeto y la sentencia los hubiera enjuiciado en los términos en que habían sido planteados. Así procede hacerlo en el presente caso en el que, al no haberse recurrido el texto refundido, la cuestión ha de enjuiciarse respecto de los artículos impugnados de la LPI, proyectándose lo que sobre ellos se resuelva a los reproducidos en el citado texto» (f.j. 2).

«Pero antes de hacerlo, procede examinar lo alegado por las partes en cumplimiento del trámite del art. 84 LOTC que les fue conferido:

A) Los arts. 129 y 130.5 de la LPI, referidos al Registro de la Propiedad Intelectual e impugnados exclusivamente por el Gobierno Vasco, que han sido, como hemos visto, modificado el primero, y derogado el segundo por la Ley 20/1992, de 7 de julio, y el contenido del citado art. 129, en la redacción que le dio la mencionada Ley, es reproducido por el vigente art. 139 del TRLPI. En relación con ambos preceptos, tanto la representación procesal del Gobierno de la Nación como la del Gobierno Vasco han manifestado en sus respectivos escritos que la controversia competencial ha perdido su objeto como consecuencia de la modificación del art. 129 y de la derogación del art. 130.5 por la Ley 20/1992 que, según expone el Letrado del Gobierno Vasco, recogen suficientemente las pretensiones deducidas en la demanda respecto a dichos artículos, y, a juicio del Abogado del Estado, han hecho desaparecer la más leve sombra de inconstitucionalidad, al establecer un régimen sumamente descentralizado del Registro de la Propiedad Intelectual en el que se reconocen las competencias de las Comunidades Autónomas.

En consecuencia, al no mantenerse la controversia competencial porque la representación del Gobierno Vasco considera en este punto satisfecha su pretensión y así lo reconoce el Abogado del Estado, hemos de concluir que "la disputa no está viva" y que, por tanto, por aplicación de la jurisprudencia expuesta en el fundamento anterior, ha desaparecido el objeto de la impugnación y el Tribunal no ha de pronunciarse sobre los arts. 129 y 130.5 de la LPI. 
B) En relación con los arts. 132, 134 y 144 de la LPI que regulan las facultades de autorización, revocación, control e inspección de las entidades de gestión de los derechos de propiedad intelectual, así como con el art. 143, por el que se crea la Comisión Arbitral de la Propiedad Intelectual, cuyo contenido reproducen los arts. 142, 144, 154 y 153.2, respectivamente, del Texto Refundido, las partes se muestran conformes con que la controversia competencial planteada respecto a dichos preceptos no puede darse por finalizada, manteniendo la misma en su integridad sin que en nada hayan quedado desvirtuados los argumentos esgrimidos en los escritos de interposición de los recursos de inconstitucionalidad y de contestación a las demandas.

Así pues, de acuerdo con la doctrina constitucional antes señalada, pese a la derogación de la LPI por el Texto Refundido, aún subsiste respecto de los preceptos impugnados la pretensión competencial del Consejo Ejecutivo de la Generalidad de Cataluña y del Gobierno Vasco, discutida por el Gobierno de la Nación. La persistencia de la controversia ha de ser resuelta por este Tribunal, porque así lo demandan las partes, constatando si se da o no la extralimitación competencial denunciada, entrando, por tanto, a enjuiciar la cuestión de fondo planteada» (f.j. 3).

«Previamente, agotando el examen de lo solicitado por las recurrentes con motivo del trámite del art. 84 LOTC, es necesario dar contestación a la petición formulada en sus alegaciones al amparo del art. 39.1 de la LOTC. Solicitan que en el caso de que este Tribunal estime su pretensión de inconstitucionalidad respecto a los arts. 132, 134, 143 y 144 de la LPI dicho pronunciamiento se extienda por conexión y consecuencia a los arts. 142, 144, 153 y 154 del Texto Refundido.

$\mathrm{El}$ art. 39.1 de la LOTC que, efectivamente permite extender el pronunciamiento de este Tribunal a otras normas distintas de las específicamente impugnadas, requiere, como pronto tuvo ocasión de señalar, la concurrencia de los tres requisitos siguientes: $1^{\circ}$ ) que la sentencia declare la inconstitucionalidad de los preceptos impugnados o de alguno de ellos; $2 .^{\circ}$ ) que exista una relación de conexión o de consecuencia entre los preceptos declarados inconstitucionales y aquellos otros a los que la inconstitucionalidad se extiende o se propaga; y $\left.3 .^{\circ}\right)$ que estos últimos pertenezcan o queden comprendidos en la misma Ley, Disposición o acto con fuerza de Ley (STC 11/1981, f.j. 27). Así pues, el art. 39.1 de la LOTC fija a este Tribunal un límite en su aplicación: que las únicas normas a las que podrá extender, en su caso, la declaración de inconstitucionalidad tienen que pertenecer o estar comprendidas en la misma Ley o Disposición con fuerza de Ley que sea objeto de la sentencia (SSTC 86/1992, f.j. 2; $67 / 1985$, f.j. 2). No es éste el caso ahora enjuiciado, porque los preceptos a cuya extensión se refieren los recurrentes, no están comprendidos en la LPI 
que es la Ley impugnada. Por tanto dicha petición no puede encontrar cobertura, como entienden las Comunidades Autónomas actoras, en el citado art. 39.1 de la LOTC.

Ahora bien, aunque, ciertamente, no es aplicable el art. 39.1 LOTC porque los artículos a los que, por extensión, puede alcanzar nuestra declaración de inconstitucionalidad han de ser "de la misma Ley", el hecho de su reproducción en el Texto Refundido permite, dada la naturaleza y contenido propios de la refundición, que este Tribunal pueda apreciar en su sentencia que la argumentación impugnatoria por ser igualmente atinente a los preceptos reproducidos, se proyecte sobre éstos en el caso de que conduzcan a una decisión de inconstitucionalidad.

En la STC 61/1997 anteriormente referida, dijimos que el texto refundido, como tal, "carece técnicamente de capacidad innovadora, con lo que la controversia competencial puede trasladarse, prácticamente en los propios términos a sus disposiciones" (f.j. 3). De ahí que, como se dice en esta sentencia y en la doctrina ya expuesta en el fundamento segundo, hay que partir de que no pueden establecerse reglas de alcance general para determinar los efectos que en nuestras sentencias hayan de producir las sucesivas disposiciones legales que se dicten en relación con las normas impugnadas o, incluso, su derogación, sino que ha de examinarse caso por caso para ponderar los verdaderos efectos y el alcance que represente la nueva normativa respecto de la que ha sido recurrida. Y si de este análisis resulta que, pese a las sucesivas disposiciones legales que se han dictado en relación con la LPI y que han hecho aconsejable su refundición, los preceptos concretamente impugnados están reproducidos en el nuevo texto, en la medida en que así sea y que como ha ocurrido en este caso, las Comunidades Autónomas recurrentes mantengan sus impugnaciones, lo que se razone sobre las mismas en orden a la declaración de inconstitucionalidad de los preceptos que son objeto de los recursos, habrá de proyectarse sobre las "nuevas" normas y producir, por tanto, respecto de ellas la misma consecuencia de inconstitucionalidad. En este punto, como vemos, el caso que ahora enjuiciamos, aunque en sentido inverso, guarda gran similitud con el resuelto por la STC 61/1997. En esta sentencia, la impugnación del texto refundido permitió trasladar el enjuiciamiento de los preceptos impugnados de la Ley a los que en dicho texto se reproducían; mientras que en el presente caso, al no estar recurrido como tal el texto refundido, el enjuiciamiento de los preceptos de la Ley permite trasladar sus efectos a su reproducción en el texto refundido» (f.j. 4).

Fallo: $1 .^{\circ}$ Declarar que la impugnación de los arts. 129 y 130.5 de la Ley 22/1987, de 11 de noviembre, de Propiedad Intelectual, formulada en el recurso interpuesto por el Gobierno Vasco, ha quedado sin objeto por derogación sobrevenida de los mismos. 
2. Estimar parcialmente los recursos de inconstitucionalidad interpuestos por el Consejo Ejecutivo de la Generalidad de Cataluña y el Gobierno Vasco contra determinados artículos de la Ley 22/1987, de 11 de noviembre, de Propiedad Intelectual, y, en consecuencia, declarar contrarios al orden constitucional de competencias, en los términos expresados en el último párrafo del fundamento jurídico undécimo de esta sentencia, los aps. $1 .^{\circ}$ (excepto el inciso inicial) y $3 .^{\circ}$ del art. 144 de la citada Ley y, por tanto, su actual reproducción por los aps. $1 .^{\circ}$ y $3 .^{\circ}$ del art. 154 del Texto Refundido de la Ley de Propiedad Intelectual, aprobado por Real Decreto Legislativo 1/1996, de 12 de abril, cuyas facultades corresponden dentro de sus respectivos territorios a las Comunidades Autónomas recurrentes.

\section{Desestimar los recursos en todo lo demás.}

(Sentencia n. ${ }^{\circ}$ 196/1997, de 13 de noviembre. Pleno. BOE 12 de diciembre de 1997. F. García-Mon y González Regueral. Votos particulares formulados, el primero por T. S. Vives Antón, y el segundo, por C. Viver Pi-Sunyer, al que se adhiere P. Cruz Villalón).

\section{JURISDICCIÓN CONTENCIOSO-ADMINISTRATIVA}

1. Recurso de amparo núm. 4033/1995 contra la Sentencia de la Sala de lo Contencioso-Administrativo del Tribunal Superior de Justicia de Madrid, de 17 de octubre de 1991, por la que se estima el recurso contencioso-administrativo promovido por el Ayuntamiento de Madrid, contra la Resolución del Tribunal Económico-Administrativo Provincial de Madrid, de 16 de noviembre de 1987. La recurrente en amparo alega indefensión al no habérsele emplazado en el proceso instado por el Ayuntamiento de Madrid con las formalidades exigidas por la Ley de Enjuiciamiento Civil, haciéndolo a través de "mandataria verbal». El TC entiende que no existe vulneración del derecho fundamental a obtener la tutela efectiva de Jueces y Tribunales, y deniega el amparo.

«Debe analizarse si el emplazamiento se llevó a cabo de manera personal y adecuadamente para que llegara a conocimiento de la destinataria del mismo. En el presente supuesto la situación ofrece ciertas características específicas, toda vez que en el domicilio obrante en autos de la recurrente se dejó por la correspondiente comisión judicial la oportuna notificación, compareciendo el día 20 de marzo de 1991 en la sede de la Sala de lo Contencioso-Administrativo del Tribunal Superior de Justicia de Cataluña, tal consta en las actuaciones, una persona llamada doña M. F. que aparece identificada por ella misma como "mandataria verbal" de la destinataria, a los efectos de que se procediera a la 
práctica de la diligencia de emplazamiento, cuyo anuncio se había producido en virtud de la notificación a la que se ha hecho referencia. Dicha diligencia de emplazamiento se llevó efectivamente a cabo en la persona de la indicada "mandataria verbal", debiéndose tener en tal caso como debidamente cumplimentados los requisitos procesales que al efecto se establecen en el 274 LECiv, en relación con los arts. 267 y 268 y concordantes de la misma, preceptos que son de aplicación de manera supletoria al orden contencioso-administrativo conforme se especifica en la disposición adicional sexta de la LJCA (SSTC $15 / 1996$ y $134 / 1995)$.

Efectuadas las anteriores consideraciones, es evidente que las reglas más elementales de la lógica permiten inferir que, en efecto, doña M. F. se encontraba vinculada con doña M. B. A. (que es la recurrente en amparo) por el mandato consistente en la práctica en su persona de la diligencia de emplazamiento que oportunamente le había sido notificada a ésta, pues de otro modo no se alcanza a comprender la presencia de doña M. F. en la indicada sede judicial como tal mandataria verbal de la recurrente, si no es actuando aquélla personal y jurídicamente como tal mandataria verbal, por ello, con las exigencias propias de tal vinculación, a consecuencia de las cuales venía obligada necesariamente no sólo a cumplir dicho encargo, si no a dar cuenta de las operaciones, actos o gestiones realizadas como tal mandataria, es decir, de la diligencia de emplazamiento llevada a cabo en su persona, a la ahora recurrente como mandante que era de ella, de lo que finalmente cabe deducir el conocimiento suficiente que doña M. B. A. tenía y ha tenido de la existencia del recurso contencioso administrativo origen del presente amparo, lo que le hubiera permitido la pretendida efectividad de la tutela judicial cuya quiebra se denuncia, mediante el ejercicio adecuado de su derecho de comparecencia y de defensa, no existiendo, en definitiva, como ha quedado dicho, la alegada situación de indefensión como quiebra del derecho fundamental, pues si la misma se produjo, tal indefensión fue propiciada voluntariamente por la recurrente ante su evidente falta de actuación en el procedimiento judicial, pese a tener noticia y conocimiento bastante de su existencia en virtud de la diligencia de emplazamiento practicada» (vid. ff.jj. 2 y 3 ).

Fallo: Denegar el amparo solicitado.

(Sentencia n. ${ }^{\circ}$ 110/1997, de 3 de junio. Sala Primera. BOE 4 de julio de 1997. E. Ruiz Vadillo).

2. Recurso de amparo núm. 3884/1996, interpuesto contra el Auto de la Sección Séptima de la Sala Tercera de Tribunal Supremo, de 18 de septiembre de 1996, que inadmite el recurso de casación por el cauce de la Ley 
RESEÑA DE SENTENCIAS DEL TRIBUNAL CONSTTTUCIONAL ...

62/1978, interpuesto contra la Sentencia dictada por la Sala de lo Contencioso-Administrativo del Tribunal Superior de Justicia de Andalucía (Málaga), de 31 de enero de 1995 , en relación con una resolución del organismo de Recaudación Ejecutiva de la Delegación de Hacienda de la Junta de Andalucía acordando el embargo de una determinada cuenta corriente por importe de algo más de 600.000 pesetas. El recurrente en amparo alega que la decisión de inadmitir el recurso de casación por no cumplir el requisito de cuantía mínima de 6 millones de pesetas lesiona su derecho a la tutela judicial efectiva, en la vertiente de acceso a los recursos. El TC entiende que no existe vulneración del derecho fundamental a obtener la tutela efectiva de Jueces y Tribunales puesto que la decisión de inadmisión del Tribunal Supremo está debidamente motivada, y no puede ser calificada de arbitraria, ilógica o no conforme con la razón, y, en consecuencia, deniega el amparo.

«Específicamente, respecto del acceso al recurso de casación que, como queda dicho rechazó el Tribunal Supremo en el Auto de 18 de septiembre de 1996, la presente demanda plantea el problema de si en relación con los derechos fundamentales de la persona y en el marco de la Ley 62/1978 es atendible, a los efectos del acceso al recurso de casación, el criterio de la cuantía del mismo o por el contrario, cualquiera que sea ésta, el recurso estará abierto sin restricción alguna por esta razón.

En este sentido conviene tener presente lo siguiente:

A) La Ley 62/1978, de Protección Jurisdiccional de los Derechos Fundamentales, comprende en su ámbito de aplicación, de acuerdo con lo establecido en el art. 1.2, la libertad de expresión, reunión, y asociación la libertad y secreto de la correspondencia, la libertad religiosa y la de residencia, la garantía de la inviolabilidad del domicilio, la protección jurídica frente a las detenciones ilegales y, en general, frente a las sanciones impuestas en materia de orden público, aunque, de acuerdo con la disposición transitoria segunda, apartado segundo de la LO 2/1979, de 3 de octubre, de este Tribunal, el ámbito de aplicación de la Ley se extiende, a partir de dicha modificación, a todos los derechos y libertades a que se refiere el art. 53.2 CE en tanto no se lleven a cabo legislativamente sus previsiones como ha sucedido con las leyes que en efecto han desarrollado el contenido de este precepto.

B) Con independencia de que se haya o no producido en este caso la lesión del derecho fundamental invocado por la recurrente, respecto del embargo de una cuenta corriente de su titularidad, que según manifiesta se ha llevado a cabo sin su previo conocimiento por causa sólo imputable a la Administración, tema éste que queda por completo al margen de este recurso, es lo cierto que 
atendida la circunstancia de que la Sala de lo Contencioso-Administrativo del Tribunal Superior de Justicia de Andalucía admitió en su momento la demanda por el cauce de la citada Ley 62/1978 aunque no diera lugar a la pretensión, ello es signo que prima facie, a los efectos procesales consiguientes, evidencia que se estaba ante un derecho fundamental que, en este caso, vendría a coincidir con el derecho al secreto bancario, y a la no invasión del mismo, salvo los supuestos establecidos en la Ley.

C) El Tribunal Supremo, en el Auto reseñado de 18 de septiembre de 1996, declara inadmisible el recurso de casación, de acuerdo al art. 93.2 b) de la Ley de la Jurisdicción, porque entiende, siguiendo la orientación marcada en SSTS 11 de noviembre y 1 de diciembre de 1994 que la invocación de un derecho fundamental como motivo del proceso no modifica el régimen general sobre la procedencia de los recursos con arreglo al contenido material del acto administrativo.

D) Conforme se indicó en la STC 37/1995, el sistema de recursos se incorpora a la tutela judicial en la configuración que le de cada una de esas leyes de enjuiciamiento reguladoras de los diferentes órdenes jurisdiccionales, sin que ni siquiera exista un derecho constitucional a disponer de tales medios de impugnación siendo imaginable, posible y real la eventualidad de que no existan, salvo en lo penal (SSTC 140/1985, 37/1988 y 106/1988). Pues bien, en el diseño del sistema de recursos se utilizan variadas modalidades y diversos tipos, cuya consideración desde la perspectiva constitucional no puede ser la misma. Por una parte están los ordinarios, como la apelación, que implica, con el llamado efecto devolutivo, la asunción por el Juez ad quem o superior, de la plena jurisdicción sobre el caso, en idéntica situación que el Juez de origen, $a$ $q u o$, no sólo por cuanto respecta a la subsunción de los hechos en la norma sino también para la determinación de tales hechos a través de la valoración de la prueba dando lugar a un novum iaditium (STC 272/1994). Por otra parte, cuando históricamente aparece la casación civil y penal, su sede se situó en el Tribunal Supremo, generalizándose después para los demás órdenes jurisdiccionales especialmente, una vez promulgada la Constitución, para la jurisdicción contencioso-administrativa por la Ley 10/1992, de 30 de abril, con la función de preservar la pureza de la ley para conseguir la igualdad y la seguridad jurídica en su aplicación, donde tiene su origen la doctrina legal con valor complementario del ordenamiento jurídico (art. 1.6 CC). Este recurso con fundamento en motivos tasados, numerus clausus, que sólo permite revisar la interpretación del Derecho, dejando intocados los hechos que dieron por ciertos los Jueces de la instancia, está clasificado entre los extraordinarios y, en consecuencia, su admisibilidad queda sometida no sólo a los requisitos meramente extrínsecos - tiempo y forma - y a los presupuestos comunes exigibles para el ordinario de apelación, sino a otros intrínsecos, sustantivos, relacionados con 
el contenido y viabilidad de la pretensión, cuyo régimen es más severo por su propia naturaleza (STC 37/1995), pues a diferencia del contemplado en la STC $188 / 1994$, que era de cuantía inestimable, en el presente que nos ocupa no lo es. Lo que hace entrar en juego la summa gravaminis de los 6.000 .000 de pesetas, requerida por el art. 93.2 b) LJCA, que cierra las puertas a la interposición del recurso de casación, presupuesto de dicho recurso que este Tribunal ha declarado reiteradamente razonable, por lo que su aplicación no conculca el derecho a la tutela judicial efectiva (art. 24.1 CE)» (f.j. 4).

«Proyectando cuanto queda dicho al recurso objeto de esta resolución hay que decir que la decisión del Tribunal Supremo debidamente motivada no puede ser calificada de arbitraria, ilógica o no conforme con la razón, lo cual es perfectamente compatible con la afirmación según la cual, otra u otras interpretaciones también pudieran ser conformes al orden constitucional.

Por último, como ya se afirmó en la STC 37/1995 no habiéndose cerrado la vía del recurso arbitrariamente o intuitu personae, queda en pie nuestra doctrina a] respecto, en cuya virtud corresponde al Tribunal Supremo la última palabra sobre la admisibilidad de los recursos de casación ante él interpuestos, a salvo lo dispuesto en materia de garantías constitucionales (art. $123 \mathrm{CE}$ ). En definitiva, la balanza constitucional no puede inclinarse en ningún sentido para optar entre dos soluciones igualmente razonables, sin interferir en el núcleo de la potestad de juzgar cuya independencia de criterio predica la Constitución, ya que el amparo no está configurado como una última instancia ni tiene una función casacional, operantes una y otra en el ámbito de la legalidad (STC 37/1995)» (f.j. 5).

Fallo: Denegar el amparo solicitado.

(Sentencia n. ${ }^{\circ}$ 125/1997, de 1 de julio. Sala Primera. BOE 18 de julio de 1997. E. Ruiz Vadillo. Votos particulares formulados por V. Gimeno Sendra y M. Jiménez de Parga y Cabrera).

3. Recursos de amparo acumulados núms. 1330/1994 y 1333/1994, promovidos contra la Sentencia de la Sala de lo Contencioso-Administrativo con sede en Burgos del Tribunal Superior de Justicia de Castilla-León, de 29 de enero de 1993, así como contra los Autos de ejecución de la misma Sala de 22 de diciembre de 1993 y 22 de febrero de 1994, denegatorios de la solicitud de apertura de incidente de ejecución de sentencia planteado frente a la misma, todos ellos relativos a Resolución del Pleno del Excmo. Ayuntamiento de San Ildefonso de la Granja (Segovia), sobre adjudicación de viviendas sociales. Los demandantes de amparo entienden que se 
ha producido la vulneración del derecho a la tutela judicial efectiva y a no padecer indefensión, del art. 24.1 CE, por cuanto fue dictada sentencia por la que se les privaba de un derecho sin haber sido previamente oídos ni debidamente emplazados al proceso. El TC otorga el amparo.

«Se limita el presente proceso a plantear la posible lesión del derecho de los recurrentes a acceder a la Justicia en defensa de sus derechos e intereses legítimos (art. 24.1 CE) en un supuesto en que, presentado recurso contencioso-administrativo impugnatorio de un Acuerdo Municipal por el que resultaban adjudicatarios de viviendas sociales en alquiler, el órgano judicial emplazó sólo a la Administración y publicó en el "Boletín Oficial de la Provincia" (de 5 de abril de 1989) anunció de la admisión a trámite del recurso, advirtiendo además que tal anuncio serviría de emplazamiento a los posibles coadyuvantes de la Administración, con el resultado de que éstos, según alegan, nunca fueron emplazados directa y personalmente para comparecer al proceso pese a su indudable interés en la conservación del Acuerdo de adjudicación.

Por su parte, la demandante en el proceso de origen y el Ayuntamiento de San Ildefonso-La Granja, aun partiendo de que efectivamente los recurrentes debieron ser personalmente emplazados,niegan relevancia constitucionala esta irregularidad por entender que, si no procesalmente, los actores en este proceso necesariamente sí tuvieron conocimiento del litigio en cuestión por la gran trascendencia del mismo en un ámbito social tan limitado como el correspondiente a la zona donde se situaban las viviendas adjudicadas, trascendencia acentuada por su reflejo en los medios locales de comunicación. El Fiscal, por último, niega la existencia de vulneración en los derechos fundamentales de los recurrentes apoyándose en la inexistencia de perjuicio material alguno que se siguiera de su no comparecencia al proceso, pues los términos de la resolución impugnada demuestran la inutilidad, en todo caso,de que acudieran o no al proceso contencioso» (f.j. 1).

«En definitiva, pues, la falta de emplazamiento personal de quienes eran indudables titulares de un interés directo en la validez del acto impugnado y fácilmente identificables según los datos de que dispuso el órgano sentenciador -basta con la relación de adjudicatarios contenida en los folios 73 y siguiente de las actuaciones judiciales remitidas-, supuso una clara y directa vulneración de su derecho a la defensa en juicio. Desechado además, por indemostrado, que los propios recurrentes contribuyeran con un comportamiento negligente a la producción de esa vulneración de sus derechos, la concesión del amparo pretendido se impone con naturalidad» (f.j. 5).

Fallo: Otorgar el amparo solicitado y, en su virtud: 
RESEÑA DE SENTENCIAS DEL TRIBUNAL CONSTTTUCIONAL ...

1. Declarar que se ha vulnerado el derecho de los recurrentes a la tutela judicial efectiva sin indefensión.

2. Restablecerles en su derecho y, a este fin, declarar la nulidad de la Sentencia de la Sala de lo Contencioso-Administrativo con sede en Burgos del Tribunal Superior de Justicia de Castilla y León de 29 de enero de 1993, recaída en Recurso núm. 1168/1989.

3. Retrotraer las actuaciones al momento procesal en que debieron ser emplazados personalmente los interesados en el procedimiento y ulterior proceso contencioso-administrativo.

(Sentencia n. ${ }^{\circ}$ 144/1997, de 15 de septiembre. Sala Segunda. BOE 16 de octubre de 1997. J. D. González-Campos).

4. Recurso de amparo núm. 809/1995 interpuesto contra el Auto de la Sala de lo Contencioso-Adminsitrativo del Tribunal Superior de Justicia de las Islas Baleares de 7 de febrero de 1995, ratificando en súplica una Providencia adoptada el 28 de diciembre de 1994, por la que se ordenó el archivo de las actuaciones por incumplimiento del trámite de comunicación previa a la Administración (en este caso al Ayuntamiento de Palma) exigido por el art. 110.3 de la Ley 30/1992. El recurrente en amparo imputa al órgano judicial hacer una interpretación rigurosa y literal de un requisito subsanable, vulnerando asi el derecho fundamental a obtener la tutela efectiva de Jueces y Tribunales. El TC remitiendo a la doctrina de la STC 76/1996 que configura la omisión del trámite de comunicación previa a la Administración como un requisito subsanable, otorga el amparo.

«Es evidente que el art. 110.3 de la Ley 30/1992, de 26 de noviembre, para el Régimen Jurídico de las Administraciones Públicas y del Procedimiento Administrativo Común, así como el 57.2 f) de la Ley reguladora de la Jurisdicción Contencioso-Administrativa, establecen de consuno una carga procesal con un contenido informativo, sin prever ningún efecto desfavorable por su incumplimiento. Por tanto, en ningún aspecto inciden sobre la efectividad de la tutela judicial, que no resulta menoscabada para nada. Se trata de una norma, una lex imperfecta, categoría doctrinalmente conocida de antiguo, que configura un deber, pero no contempla la sanción por su inobservancia. Conviene dejar sentado, antes de seguir más allá en el discurso, que parece plenamente razonable la exigencia de comunicar previamente al órgano administrativo, autor del acto impugnado, el hecho de haberse interpuesto recurso contencioso-administrativo contra él. Sin embargo los derechos al acceso a la justicia y a la defensa en juicio se han visto debilitados hasta su mínima expresión por obra de una seve- 
ra y restrictiva interpretación, jurisprudencial, dando una trascendencia desmesurada, desproporcionada en suma al incumplimiento de esa carga procesal informativa, pues se le hace producir la inadmisibilidad de la pretensión.

Tal efecto irreversible no está en la Ley sino en su aplicación. Una medida negativa y desfavorable, que limite los derechos fundamentales indicados hasta hacerlos eventualmente imposibles, sólo podría ser establecida expresamente en la Ley y aun así cabría dudar de su constitucionalidad, pero en ningún caso puede nacer por inducción o deducción, por inferencia o presuntivamente. Una tal lectura impide el acceso a los Jueces y Tribunales por tratarse del ejercicio de pretensiones. En tal encrucijada, el camino correcto ha de consistir en el reconocimiento de que, no siendo la Ley, en sí misma, contraria a la Constitución (art. 24), es sin embargo viable el amparo, porque su interpretación en la decisión judicial impugnada condujo a un resultado que nulificaba la efectividad de la tutela judicial.

Esta es, en síntesis, la ratio decidendi o fundamento último de nuestra STC 76/1996 donde se dan por buenos los preceptos legales en cuestión, siempre que la omisión de la comunicación previa se conciba como defecto subsanable sin convertirse en causa de la inadmisibilidad de la pretensión, por resultar desproporcionada tal consecuencia "en relación con el contenido esencial del art. 24.1 CE y, por tanto, inconstitucional". Pues bien, en el caso que nos ocupa ahora como en los procesos a los cuales pusieron fin las SSTC 83/1996, $84 / 1996,19 / 1997$ y 65/1997, la Sala de lo Contencioso-Administrativo del Tribunal Superior de Justicia de las Islas Baleares optó por una interpretación puramente literal de los sobredichos preceptos que condujo a considerar insubsanable la falta de tal comunicación previa con la consecuente inadmisión a limine del recurso contencioso-administrativo interpuesto por quien aquí solicita amparo. Tal decisión, que le impide obtener una respuesta sobre el fondo de su pretensión, menoscaba drásticamente la efectividad de la tutela judicial hasta volatilizarla y, por ello, ha de dársele el amparo que nos pide, para lo cual se hace necesaria la retrocesión de las actuaciones hasta el momento inmediatamente anterior a aquel donde se acordó la inadmisión del recurso y su archivo, con el fin de que la Sala de lo Contencioso-Administrativo del Tribunal Superior de Justicia de las Islas Baleares haga lo procedente según lo que se dice al respecto en esta sentencia» (f.j. 2).

Fallo: Otorgar el amparo solicitado y, en consecuencia:

1. Declarar que se ha lesionado a la recurrente su derecho a la tutela judicial efectiva. 
2. $\quad$ Restablecerla en su derecho y, a tal fin, declarar la nulidad de la providencia y del Auto dictados respectivamente el 28 de diciembre de 1994 y el 7 de febrero de 1995 por la Sala de lo Contencioso-Administrativo del Tribunal Superior de Justicia de las Islas Baleares en el recurso contencioso-administrativo núm. 1707/1994, ordenando retrotraer las actuaciones del mismo al momento anterior al pronunciamiento de aquella providencia a fin de que por la referida Sala se adopte resolución que permita la plena efectividad del derecho a la tutela judicial efectiva de la actora.

(Sentencia n. ${ }^{\circ}$ 152/1997, de 29 de septiembre. Sala Segunda. BOE 30 de octubre de 1997. R. de Mendizábal Allende).

5. Recurso de amparo núm. 2652/1994 dirigido contra la Sentencia de la Sala de lo Contencioso-Administrativo del Tribunal Superior de Justicia de Cantabria de 4 de mayo de 1994, que estimó el recurso deducido por la Asociación para la Defensa de los Recursos Naturales de Cantabria y anuló la Licencia de obras concedida por el Ayuntamiento de Arnuero a la Inmobiliaria Arnuero, S.A. para la construcción de ciertas viviendas en la localidad de Isla. Asimismo se impugna la providencia y el Auto de la citada Sala de 31 de mayo y 29 de junio de 1994 por los que se inadmite la personación de los ahora recurrente en amparo en el proceso contencioso en el que había recaído la referida sentencia en calidad de terceros titulares de intereses legítimos. Alegan los demandantes de amparo haber sufrido indefensión al haberse seguido el recurso contencioso-administrativo en el que se debatía la legalidad de la licencia de obras que autorizó la construcción de sus viviendas, sin haber sido emplazados y sin permitirles la personación, a pesar de que en el acto impugnado les afectaba y de que el procedimiento constaba que eran titulares de las referidas viviendas cuya demolición finalmente se ordenaba en la sentencia recaída. El TC entiende que existe una vulneración del derecho fundamental a obtener la tutela efectiva de Jueces y Tribunales y otorga parcialmente el amparo.

«En el presente caso, no cabe duda que los hoy actores eran titulares de un interés legítimo en el sentido del art. 24.1 CE. De los antecedentes expuestos se deduce que los demandantes adquirieron mediante contrato de compraventa las viviendas construidas por la inmobiliaria coadyuvante en el proceso. De manera que, según iban comprando las referidas viviendas iban asumiendo la condición de "titulares legítimos" en el proceso en trámite en el que se debatía la legalidad de la licencia de obras a cuyo amparo se construyeron las viviendas, y cuya anulación determinaba, sin duda, un claro efecto negativo para sus intereses, tan grave y manifiesto como es el derribo de aquello que habían adquiri- 
do con anterioridad. Así las cosas, puede válidamente sostenerse que los actores ostentaban un interés directo, propio y específico, por ser los compradores de las viviendas cuya demolición se ordenaba por el órgano judicial en virtud de su pronunciamiento la anulación de la Licencia de obra que en su día las autorizó.

Frente a tal conclusión no resultan admisibles los razonamientos expuestos por el Ministerio Fiscal en orden a la personación de los ahora demandantes de amparo. Justifica su tesis, en base a la condición de interesados legítimos de los recurrentes, con el argumento de que, en realidad tal condición surgió en el momento en que se otorgaron las correspondientes escrituras públicas de compraventa, negocio jurídico que determinaría el nacimiento de tal cualidad de interesados en el proceso. Sin embargo, tal argumentación no se corresponde con los efectos que produce el contrato de compraventa suscrito entre la inmobiliaria y los hoy actores. En nuestro Derecho, aun cuando no se haya otorgado la correspondiente escritura pública, basta el acuerdo de voluntades de las partes, adquirente y vendedora, para que surja el consentimiento contractual y, por tanto, para que se perfeccione el contrato, que permite la transmisión de la propiedad si concurre la traditio. Así las cosas, en tanto se fueron celebrando los distintos contratos de compraventa, los compradores se fueron convirtiendo en "interesados legítimos en el proceso", en el que se debatía la legalidad de la Licencia Municipal de obras, y que concluyó con la decisión judicial de demolición de lo edificado» (vid. f.j. 4).

«Partiendo, pues, de que los demandantes de amparo ostentaban la titularidad de un derecho subjetivo derivado del acto impugnado, debemos examinar si la actuación del órgano judicial fue, desde la perspectiva del derecho fundamental reconocido en el art. 24.1 CE, correcta, aunque hay que poner de manifiesto que este dato no constaba inicialmente en el expediente administrativo.

Hemos dicho en la STC 65/1994 que no basta con ostentar un interés legítimo para hacer exigible la citación a juicio, sino que es necesario que tal circunstancia conste en el expediente administrativo y pueda ser conocida por la Sala. En concreto, hemos afirmado en la referida sentencia que la obligación de emplazar personalmente se refiere únicamente a quienes constan en las actuaciones judiciales o en el expediente administrativo como titulares de derechos o intereses legítimos, $y$, por tanto, no incluye a los que después de haberse resuelto éste e iniciado el proceso contencioso, adquieren fuera de él la antedicha cualidad en virtud de actos posteriores y derivados del objeto del proceso. La adquisición de derechos subjetivos y de intereses legítimos sobrevenidos después de la interposición abre a los titulares la posibilidad de comparecer o actuar en el procedimiento ya en marcha como codemandados o coadyuvantes en virtud del emplazamiento edictal o por propia iniciativa, pero carece de rele- 
RESEÑA DE SENTENCIAS DEL TRIBUNAL CONSTITUCIONAL ...

vancia en la fase inicial para imponer a la oficina judicial la obligación de emplazar a quien no se conoce.

Pues bien, de lo actuado se desprende que no constaba en el expediente administrativo, ni tampoco en el momento de la iniciación del procedimiento judicial, ningún dato sobre la existencia e identidad de los solicitantes de amparo y sí, únicamente, de la inmobiliaria codemandada. En ese momento, puede afirmarse que la Sala de lo Contencioso actuó diligentemente, toda vez que procedió a emplazar a aquellos que aparecían suficientemente identificados en las actuaciones, de manera que, en ese momento, la actuación del órgano judicial fue correcta.

Posteriormente la Sala de lo Contencioso-Administrativo tuvo formal conocimiento de la existencia de los demandantes en amparo, como titulares de derechos e intereses legítimos, puesto que la entidad codemandada al contestar la demanda, aportó los contratos de compraventa que con anterioridad había suscrito con aquéllos, si bien, como ya se dijo, en ellos no constaban los domicilios de los compradores de los pisos. La Sala de lo Contencioso no otorgó ninguna relevancia a tal dato, y sin atribuirle ninguna trascendencia procesal, acordó la continuación del procedimiento, dejando al margen a los actores en este proceso de amparo.

Pero incluso, partiendo por vía de hipótesis de que constando a través de las correspondientes letras de cambio, los domicilios de los compradores - librados en el negocio jurídico cambiario- hay que advertir que no tienen por qué coincidir necesariamente aquéllos con el domicilio real y además, por otra parte, debemos señalar, que llevar a cabo, en estas circunstancias, el emplazamiento de personas que figuraban como compradoras hubiera producido un retraso desmesurado en la tramitación del proceso contencioso-administrativo» (f.j. 5).

«Resta por analizar la ulterior actuación de la Sala que, una vez dictada la sentencia, inadmite la personación de los demandantes de amparo.

Con toda obviedad la actuación inicial del órgano judicial fue correcta constitucionalmente cuando procedió a emplazar a la Administración autora del acto y a la Entidad titular de la licencia de obras y otro tanto debe decirse, como ya se acaba de anticipar, respecto de su actuación cuando tiene un relativo conocimiento de los codemandados, es decir, de aquellas personas que habían adquirido pisos en el inmueble y que ningún interés se manifestó respecto a su intervención en el proceso contencioso-administrativo del que por una relación con la Constructora no era demasiado aventurado presumir que conocían. 
Ahora bien, cuando los ahora recurrentes, tienen conocimiento de la sentencia dictada por el Tribunal Superior de Justicia de Cantabria presentaron un escrito a la Sala personándose en el proceso, solicitud que fue denegada por providencia de 31 de mayo de 1994 frente a la cual interpusieron recurso de súplica que fue desestimado por Auto de 29 de junio del mismo año que confirmó la inadmisión de la personación en autos de los ahora recurrentes. Y en este momento sí se produjo una situación de indefensión para los ahora demandantes en amparo pues teniendo un interés legítimo, como antes quedó dicho, no se les dio la oportunidad de defenderse, posición procesal de parte que, entre otras cosas, podía suponer, en su caso, la posibilidad de interponer el correspondiente recurso de casación, así como, el hacer valer los derechos de que se considerasen asistidos, respecto de la eventual demolición de las viviendas de las que eran titulares en la fase de ejecución provisional o definitiva» (f.j. 6).

Fallo: Otorgar parcialmente el amparo y, en su consecuencia,

1. Reconocer el derecho de los recurrentes a la tutela judicial efectiva (art. 24.1 CE) sin indefensión.

2..$^{-}$Declarar la nulidad de la providencia de 31 de mayo de 1994, dictada por la Sala de lo Contencioso-Administrativo del Tribunal Superior de Justicia de Cantabria así como el Auto de 29 de junio de 1994, recaído en el recurso contencioso-administrativo núm. 111/1993.

3. Retrotraer las actuaciones al momento procesal oportuno a fin de que por la Sala, al resolver sobre la solicitud de personación de los actualmente demandantes en amparo, se dicte la resolución que proceda en derecho, y que sea respetuosa con el derecho a la tutela judicial efectiva sin indefensión de los recurrentes.

(Sentencia n. ${ }^{\circ}$ 192/1997, de 11 de noviembre. Sala Primera. BOE 12 de diciembre de 1997. E. Ruiz Vadillo).

6. Recurso de amparo núm. 1184/1993, promovido contra la Sentencia del Tribunal Superior de Justicia de Andalucía (Sala de lo Contencioso-Administrativo en Sevilla, Sección Prinera) de 23 de diciembre de 1992 que estimó el recurso interpuesto contra el Ayuntamiento de Prado del Rey (Cádiz) sobre provisión interina de una plaza de policía local. El actor, que había sido nombrado interinamente Policía municipal por el Ayuntamiento de Prado del Rey, pide amparo contra la Sentencia que anuló su nombramiento, y declaró el mejor derecho de otro de los aspirantes. La razón es que la Sala de lo Contencioso-Administrativo de Sevilla no le em- 
RESEÑA DE SENTENCLAS DEL TRIBUNAL CONSTITUCIONAL ...

plazó personalmente, sumiéndole en una situación de indefensión contraria al derecho fundamental del artículo 24.1 CE. El TC deniega el amparo al entender que hubo conocimiento extraprocesal de las actuaciones y una ausencia de la debida diligencia en defensa de derechos e intereses legítimos.

«Tal y como hemos razonado en supuestos similares, aun cuando no hay absoluta constancia de que el solicitante de amparo tuviera conocimiento del proceso contencioso-administrativo con anterioridad al momento en que se le comunicó la ejecución de la sentencia, puede razonablemente estimarse que no podía ignorar la existencia del mismo, conforme a las reglas del criterio humano que rigen la prueba de presunciones a que puede acudirse de acuerdo con los arts. 1249 y 1253 del Código Civil. Una vez valorados los datos expuestos, la ignorancia que alega en este proceso constitucional no es explicable en términos racionales, si se repara en el hecho de que el actor fue funcionario durante todo el tiempo que duró el contencioso, en una Administración de escaso personal; que en años sucesivos se repitieron pruebas para proveer interinamente la misma plaza, a la que se presentó de nuevo quien había interpuesto recurso judicial ante el Tribunal Superior de Justicia, quien además había formulado protestas públicamente en el municipio por haber adjudicado la plaza al señor G. H., lo que dio lugar a una causa penal por desacato, instada por el Ayuntamiento a partir del testimonio prestado, como Policía de servicio en el momento de los hechos, por el propio señor $\mathrm{G}$. $\mathrm{H}$.

Por lo demás, el mero dato de que la existencia del contencioso-administrativo, y la personación en él del Ayuntamiento como parte demandada, recibieron publicidad en el ámbito municipal hubiera sido suficiente, dado el carácter de funcionario de ese mismo Ayuntamiento del demandante de amparo. Pues la publicidad "en un instrumento como el tablón de anuncios en las oficinas públicas implica respecto a los funcionarios que trabajan en las mismas y a los que aquéllas puedan afectar una carga de conocimiento, con sus lógicas consecuencias, que no puede equipararse a la publicidad que con respecto a los ciudadanos en general representan los diarios o boletines oficiales". Pretender darse por no enterado del acuerdo de remisión del expediente administrativo y de personación en el correspondiente tablón de anuncios, "instrumento de conocimiento interno para los funcionarios destinados en la correspondiente oficina pública", no es aceptable (STC 45/1985, f.j. 3. ${ }^{\circ}$ ).

En definitiva, la no comparecencia en el proceso antecedente y, por tanto, la indefensión denunciada se debe, pues, a la pasividad del propio recurrente; por lo que no cabe alegar en amparo una indefensión que pudo evitar y no lo hizo con anterioridad a conocer el resultado desfavorable del litigio. 
Por lo expuesto, el recurso de amparo debe ser desestimado» (f.j. 6).

Fallo: Denegar el amparo.

(Sentencia n. ${ }^{\circ}$ 197/1997, de 24 de noviembre. Sala Segunda. BOE 30 de diciembre de 1997. T. S. Vives Antón).

\section{DERECHO PÚBLICO DE LA ECONOMÍA}

\section{A) Mercado de Valores}

1. Recursos de inconstitucionalidad acumulados núms. 1712/1988, 1716/1988 y 1724/1988 promovidos, respectivamente, por el Gobierno Vasco, el Parlamento de Cataluña y el Consejo Ejecutivo de la Generalidad de Cataluña, contra la Ley 24/1988, de 28 de julio, del Mercado de Valores; y conflictos positivos de competencia núms. 1527/1989 y 1924/1989, planteados por el Gobierno Vasco contra los Reales Decretos 276/1989, de 22 de marzo, de Sociedades y Agencias de Valores, y 726/1989, de 23 de junio, sobre Sociedades Rectoras y Miembros de las Bolsas de Valores, Sociedad de Bolsas y Fianza Colectiva, respectivamente. El TC los estima parcialmente delimitando el ámbito territorial y material de algunos preceptos. Dada la variedad de cuestiones abordadas en la Sentencia limitaremos la reseña a aquellos aspectos de la Ley 24/1988, de 28 de julio, del Mercado de Valores, que según el Tribunal Constitucional no son aplicables en las Comunidades Autónomas del País Vasco y Cataluña.

«El art. 45, impugnado sólo por el Consejo Ejecutivo de la Generalidad de Cataluña, condiciona la creación por las Comunidades Autónomas de las Bolsas ubicadas en su territorio a la conformidad del Gobierno de la Nación, "atendiendo a los elementos y consecuencias supracomunitarias de dicha creación". El recurrente considera que dicha condición en modo alguno se aviene con los términos en los que el art. 9.20 del Estatuto de Autonomía de Cataluña ha atribuido la competencia a Cataluña. Los intereses supracomunitarios o generales del Estado - argumenta el recurrente - ya fueron tenidos en cuenta por el constituyente a la hora de establecer la distribución competencial, y si en el Estatuto de Autonomía de Cataluña la competencia para la creación de Bolsas únicamente ha sido limitada por el respeto a la legislación mercantil, el Estado no puede invocar nuevos intereses para restringir aquella competencia. El Abogado del Estado sostiene, por el contrario, que el legislador estatal puede disponer legítimamente que el Gobierno coparticipe en la decisión sobre la creación de una Bolsa, por cuanto ésta es un fragmento del mercado bursátil nacional. 
RESEÑA DE SENTENCIAS DEL TRIBUNAL CONSTITUCIONAL ...

Ante todo debe quedar sentado que la alusión genérica e indeterminada a "los elementos y consecuencias supracomunitarias" de la creación de una Bolsa de Valores en el territorio de una Comunidad Autónoma no justifica, por sí sola, la coparticipación del Gobierno en dicha tarea, atribuida, con carácter exclusivo, por el art. 9.20 del Estatuto de Autonomía de Cataluña a la Comunidad Autónoma recurrente. No existe, por las razones que se exponen a continuación, razón alguna para que el acto de creación de una Bolsa en el territorio autonómico tenga que compartirse por el Estado y la Comunidad Autónoma correspondiente.

El Estatuto de Autonomía de Cataluña, en su art. 9.20, ha atribuido a la Generalidad de Cataluña la competencia exclusiva para establecer Centros de contratación de valores, de los que, como ha quedado dicho, las Bolsas constituyen un tipo concreto. Sin duda alguna, el establecimiento, esto es, la creación de una Bolsa de Valores ubicada en el territorio de la Comunidad Autónoma corresponde según el art. 9.20 del Estatuto de Autonomía de Cataluña, a la Generalidad, con el solo límite del respeto a la legislación mercantil, de un lado, y a las bases de la ordenación del crédito, de otro. Exigir la conformidad del Gobierno de la Nación para la creación de una Bolsa de Valores en el territorio de la Comunidad Autónoma recurrente no es una norma básica, pues su finalidad no es establecer un común denominador normativo en todo el territorio nacional que sirva de límite a la potestad normativa de la Comunidad Autónoma, sino una norma que atribuye al Estado una competencia, la de participar en el establecimiento de las Bolsas ubicadas en el territorio de Cataluña, que no le ha sido atribuida por la Constitución. Aun admitiendo que tal decisión fuese básica, nunca podría llegar a impedir el ejercicio de una competencia exclusiva autonómica, cosa que ocurriría si el Gobierno quisiera vetar la creación de una Bolsa. De acuerdo con la doctrina del Tribunal (SSTC 149/1991, f.j. 7. ${ }^{\circ}, \mathrm{A}, \mathrm{c}$ ), y 36/1994, f.j. 5.'), la concurrencia de las voluntades del Estado y de la Comunidad Autónoma para el ejercicio de una competencia sólo es constitucionalmente admisible cuando ambas voluntades resuelven sobre asuntos de su propia competencia. En el presente caso ello no es así, por cuanto que la competencia para el establecimiento de una Bolsa de Valores en su territorio corresponde en exclusiva a la Comunidad Autónoma, y por eso, la mediatización de la conformidad del Gobierno no puede convertir un acto de competencia exclusiva autonómica en un acto complejo, resultado de la concurrencia de dos voluntades, la del Estado y la de la Comunidad Autónoma. Al Estado le corresponde la competencia para establecer las bases de la ordenación del crédito y los elementos que sean necesarios para garantizar la unidad de mercado y a la Comunidad Autónoma la ejecución de dichas bases, esto es, entre otras cosas, el establecimiento, en su territorio, de Bolsas de Valores respetando ese marco básico estatal. 
Por todo lo dicho hay que concluir que el art. 45 de la Ley del Mercado de Valores, en el inciso "aunque requerirá la conformidad del Gobierno de la Nación, atendiendo a los elementos y consecuencias supracomunitarias de dicha creación", vulnera las competencias que el art. 9.20 del Estatuto de Autonomía de Cataluña ha atribuido a la Comunidad Autónoma de Cataluña» [vid. f.j. 9 , $\mathrm{B}, \mathrm{a})]$.

«También del art. 48 se dice, como del anterior, que invade sus competencias por haber llegado a tal grado de detalle en la regulación que las vacía, sin dejar margen para otras formas organizativas. Más concretamente se denuncia, tanto por el Parlamento como por el Consejo Ejecutivo de la Generalidad de Cataluña, que la aprobación de los Estatutos de las Sociedades Rectoras, así como sus modificaciones, corresponde únicamente a las Comunidades Autónomas toda vez que se trata de meras funciones ejecutivas y regladas. El Abogado del Estado, por su parte, rechaza estas imputaciones argumentando que el art. 48 constituye una base de ordenación del crédito que deja margen suficiente al desarrollo legislativo autonómico y a la ejecución.

Como ya ha quedado expuesto en el apartado anterior, y de acuerdo con la doctrina de este Tribunal Constitucional (SSTC 48/1988, f.j. 3. ${ }^{\circ}$, y 49/1988, f.j. $\left.2 .^{\circ}\right)$, las normas organizativas de las Bolsas de Valores pueden quedar comprendidas en las bases de la ordenación del crédito por cuanto que una organización existe para realizar una determinada actividad y no es, pues indiferente a la realización de dicha actividad la forma en que se integran los centros de decisión. El art. 48 de la Ley es básico porque establece un mínimo orgánico común a todas las Bolsas que está íntimamente relacionado con la actividad que en ellas se desarrolla. La existencia de una Sociedad Rectora, de la que son accionistas todos los miembros de la Bolsa correspondiente, la negación a dicha Sociedad Rectora de su condición de miembro de la Bolsa, con la consiguiente prohibición de realizar actividad alguna de intermediación financiera, y la existencia, finalmente, de un Consejo de Administración y un Director General constituyen una estructura organizativa que incide directamente en la actividad de negociación bursátil y que, por ello, se impone con carácter homogéneo para todas las Bolsas. El carácter básico de esta regulación se deriva, igualmente,del hecho de que las Sociedades Rectoras de cada Bolsa integran la "Sociedad de Bolsas" que es el órgano de gestión del Sistema de Interconexión Bursátil (SIB), de ámbito estatal. Las Comunidades Autónomas pueden, a partir de ese mínimo organizativo común, desarrollar y ejecutar sus propias decisiones, para lo que la Ley deja margen suficiente e, incluso, contiene referencias explícitas a esta posibilidad. Desde este punto de vista, el art. 48 no invade las competencias de las Comunidades Autónomas recurrentes. 
No puede decirse lo mismo, sin embargo, del último apartado del art. 48 que atribuye la aprobación y modificación de los Estatutos de las Sociedades rectoras conjuntamente a la Comisión Nacional del Mercado de Valores y a la Comunidad Autónoma correspondiente. Hay que convenir con las Comunidades Autónomas recurrentes que dicha actividad —aprobación y modificación de los Estatutos- es de naturaleza ejecutiva y, al no existir razón alguna que justifique su carácter básico, debe corresponder exclusivamente, esto es, sin el concurso de la Comisión, a la Comunidad Autónoma en cuyo territorio esté ubicada la Bolsa de cuya Sociedad Rectora se trate. Aunque, obviamente, la Comunidad Autónoma deberá ejercer su competencia en el marco básico de la Ley del Mercado de Valores.

Por tanto, debemos acoger la pretensión de los recurrentes y declarar que la atribución de la competencia establecida en el art. 48, de aprobación y modificación de los Estatutos a la Comisión Nacional del Mercado de Valores, vulnera las competencias de las Comunidades Autónomas recurrentes» [vid. f.j. 9, B, d)].

«El art. 64 regula las consecuencias de la inscripción registral de las Sociedades y Agencias de Valores, así como la obligación de acreditar previamente ante la Comisión Nacional del Mercado de Valores el cumplimiento de los requisitos exigidos por la Ley.

Los recurrentes argumentan que la acreditación del cumplimiento de los requisitos a que se refiere el precepto impugnado corresponde a las Comunidades Autónomas y no a la Comisión Nacional del Mercado de Valores, puesto que se trata de una actividad de verificación y, por tanto, ejecutiva, que corresponde a las Comunidades Autónomas cuando se trate de Sociedades y Agencias de Valores que actúen en sus respectivos territorios. El Abogado del Estado se opone a estos argumentos alegando que el art. 64 es una norma jurídico-mercantil en cuanto define la base para la conversión de las Sociedades y Agencias de Valores en operadores bursátiles y en cuanto regula una relación inter privatos (entre una Sociedad o Agencia de Valores y otras Sociedades y Agencias accionistas de una Sociedad Rectora).

$\mathrm{El}$ art. 64 es una consecuencia directa de la fórmula del apartado 3..$^{\circ}$ del art. 62 - no contestada por los recurrentes- según la cual "para poder dar comienzo a sus actividades las Sociedades y Agencias de Valores, obtenida la autorización, deberán quedar inscritas en los correspondientes Registros de la Comisión, tras su constitución e inscripción en el Registro Mercantil". En conexión con dicha regla, el art. 64, que ahora analizamos, establece que la inscripción en los correspondientes Registros (se entiende que son Registros de la Comisión Nacional del Mercado de Valores por el contexto del precepto) dará derecho a las Sociedades y Agencias a ser miembros de una o varias de las 
Bolsas de Valores, siempre que acrediten previamente ante la Comisión el cumplimiento de los requisitos que a este fin exige la Ley. Pues bien, es este requisito de la acreditación ante la Comisión lo que las Comunidades Autónomas recurrentes cuestionan.

Ante todo debe decirse que la inscripcion en los Registros correspondientes de la Comisión Nacional del Mercado de Valores es un acto posterior y distinto a la creación de las Sociedades y Agencias, esto es, posterior a la obtención de la autorización. Significa ello que de la inscripción de las Sociedades y Agencias de Valores en el Registro Mercantil, primero, y en los Registros correspondientes de la Comisión Nacional del Mercado de Valores, después, no deriva su creación, sino la adquisición de su condición de miembros de una o varias Bolsas, según participen en el capital de las Sociedades Rectoras de una o varias Bolsas de Valores. Quiere decirse con ello que el acto de verificación por la Comisión Nacional del Mercado de Valores previsto en el art. 64 -que las Comunidades Autónomas recurrentes consideran lesivo de sus competencias - se refiere al cumplimiento de los requisitos para llegar a ser miembro de una Bolsa, una vez obtenida la inscripción en los correspondientes Registros.

Dicho esto, nada hay que oponer, y nada oponen las Comunidades Autónomas, al hecho de que el Estado cree un Registro único que garantice la concentración de todos los datos relativos a las Sociedades y Agencias de Valores, ya que con ello cumple una función de información y publicidad que entra en el terreno de sus competencias sobre el mercado único de valores. Sin embargo, no puede decirse lo mismo sobre la actividad consistente en verificar el cumplimiento de los requisitos necesarios para que puedan ser considerados miembros de una o varias Bolsas. Siendo básica, y así lo hemos declarado en relación con el art. 47 de la Ley, la fijación de los requisitos necesarios para alcanzar la condición de miembro de las Bolsas,la certificación del cumplimiento de dichos requisitos es un acto reglado, de estricta comprobación de las condiciones fijadas por la Ley que posee naturaleza ejecutiva.

No hay ninguna razón - ni el Abogado del Estado la apunta tampocopara sostener que, a pesar de su naturaleza ejecutiva, la actuación de la que tratamos tenga carácter básico. Antes al contrario debemos concluir que la homogeneidad exigida por los principios de unidad de mercado y las bases de la ordenación del crédito no se rompe por el hecho de que sean las Comunidades Autónomas, con competencias en la materia, las que verifiquen si las Sociedades y Agencias de Valores cumplen los requisitos de participación en el capital de la Sociedad Rectora de la Bolsa ubicada en su territorio. Todo ello significa que —en línea con lo que sostuvimos en nuestra STC 243/1994 (f.j. 6. ${ }^{\circ}$ )— el Estado, a través de la Comisión Nacional del Mercado de Valores, puede establecer los Registros correspondientes para la inscripción de las Sociedades y 
RESEÑA DE SENTENCIAS DEL TRIBUNAL CONSTTTUCIONAL ...

Agencias de Valores pero, en tal caso, debe aceptar como vinculantes las propuestas de inscripción que efectúen las Comunidades Autónomas con competencias en la materia.

Por lo dicho, debemos declarar que el art. 64, párrafo $1 .^{\circ}$, de la Ley del Mercado de Valores, en el inciso que dice "ante la Comisión Nacional del Mercado de Valores", no respeta la distribución de competencias establecida por el bloque de constitucionalidad» (vid. f.j. 10, b).

«De la disposición adicional primera se impugna tanto el hecho de que declare que la Ley es de aplicación a las Bolsas ubicadas actualmente en el territorio de las Comunidades Autónomas recurrentes, es decir, a las Bolsas de Bilbao y Barcelona, como el cambio de denominación que impone para éstas.

En cuanto a la primera alegación hay que convenir con las Comunidades Autónomas litigantes que, en un primera aproximación a su texto, el inciso final de la disposición adicional primera no respeta la distribución de competencias que la Constitución y los Estatutos de Autonomía han previsto en materia de Bolsas de Valores. La referencia a los fundamentos jurídicos de esta sentencia en los que hemos declarado que determinados preceptos de la Ley 24/1988, incluidos algunos del capítulo segundo del Título IV (De las Bolsas de Valores), no son aplicables en las Comunidades Autónomas, pone de manifiesto que el legislador estatal no puede pretender, sin vulnerar las competencias autonómicas, que la Ley sea de íntegra aplicación a las Bolsas de Bilbao y Barcelona. Ahora bien, éste no es el único entendimiento posible de esta disposición. Cuando la Ley del Mercado de Valores impone su íntegra aplicación a las Bolsas mencionadas por su nombre, sólo puede significar que se trata de aquellos preceptos cuyo contenido, según lo declarado en la presente sentencia, no vulnere el orden constitucional de competencias.

Por lo que respecta a la imposición legal de la denominación "Bolsas de Valores" para las Bolsas sitas actualmente en el territorio de las Comunidades Autónomas recurrentes, hoy llamadas "Bolsas de Comercio", no puede sostenerse, en contra de lo que argumenta el Abogado del Estado, que esa impositio nominis tenga carácter básico por ser "un elemento de seguridad jurídica de la contratación bursátil ..., alternativamente, base de la ordenación del crédito". La seguridad jurídica, que sin lugar a dudas debe predicarse del funcionamiento de los Mercados de Valores, queda garantizada suficientemente con la denominación actual de las Bolsas, esto es, "Bolsas Oficiales de Comercio". Ni la unidad del mercado, ni la seguridad jurídica de los que operan en Bolsa se quebrantan por el hecho de que las Bolsas que en la actualidad existen en las Comunidades Autónomas recurrentes, únicas a las que se refiere la disposición adicional primera, sigan denominándose "Bolsas Oficiales de Comercio". Si el 
cambio de denominación no es, por lo que acaba de decirse, una necesidad para alcanzar las finalidades propias de la ordenación básica, hay que concluir que la previsión de la disposición adicional primera vulnera las competencias de los recurrentes» (vid. 13, a).

Fallo: 1. ${ }^{\circ}$ Estimar en parte los recursos de inconstitucionalidad contra la Ley $24 / 1988$, de 28 de julio, del Mercado de Valores, y en consecuencia:

a) Declarar que no son aplicables en las Comunidades Autónomas del País Vasco y Cataluña: el art. 45 en el inciso «aunque requerirá la conformidad del Gobierno de la Nación, atendiendo a los elementos y consecuencias supracomunitarias de dicha creación»; el inciso «Los estatutos de dichas Sociedades y sus modificaciones requerirán la previa aprobación por la Comisión Nacional del Mercado de Valores» del art. 48; el art. 64, párrafo 1. ${ }^{\circ}$, en el inciso que dice «ante la Comisión Nacional del Mercado de Valores», y la imposición del cambio de nombre de las actuales Bolsas existentes en las Comunidades Autónomas del País Vasco y Cataluña, contenida en la Disposición adicional primera.

b) Declarar que no invaden las competencias de las Comunidades Autónomas recurrentes, siempre que se interpreten de acuerdo con lo expuesto en los fundamentos jurídicos de esta sentencia que se especifican, los siguientes artículos de la Ley 24/1988: arts. 31, c) y 59 [f.j. 9, A), a)]; art. 34 [f.j. 9, A), d)]; art. 47 [f.j. 9, B, c)], y art. 78 [f.j. 11].

c) Desestimar los recursos en todo lo demás.

2. $\quad$ Estimar en parte los conflictos positivos de competencia suscitados frente a los Reales Decretos 276/1989 y 726/1989 y en consecuencia:

a) Declarar que son de la titularidad exclusiva de la Comunidad Autónoma del País Vasco las competencias de aprobación contenidas en el art. 7; las competencias de suspender y dejar sin efecto así como las de vigilancia del art. 15 , apartados 2 y 3 ; las competencias de aprobación del art. 17.2 y las competencias de fijación del importe global de la fianza y de reparto previstas en el art. 23.2; todos ellos del Real Decreto 726/1989, de 23 de junio, sobre Sociedades Rectoras y miembros de las Bolsas de Valores, Sociedad de Bolsas y Fianza Colectiva.

b) Declarar que el art. 12 del citado Real Decreto 726/1989 no invade las competencias de la Comunidad Autónoma del País Vasco siempre que sea interpretado en la forma expresada en el fundamento jurídico 18, A), c) de esta sentencia.

c) Desestimar los dos conflictos de competencia en todo lo demás. 
RESEÑA DE SENTENCIAS DEL TRIBUNAL CONSTITUCIONAL ...

(Sentencia n. ${ }^{\circ}$ 133/1997, de 16 de julio. Pleno. BOE 6 de agosto de 1997. R. de Mendizábal Allende).

\section{B) Seguros. Planes y Fondos de Pensiones}

1. Recursos de inconstitucionalidad núms. 1181/1987 y 1190/1987, promovidos, respectivamente, por el Consejo Ejecutivo de la Generalidad de Cataluna y por el Parlamento Vasco contra la Ley 8/1987, de 8 de junio, de regulación de los Planes y Fondos de Pensiones. El TC estima parcialmente y declara que el artículo 25.3, d) de la Ley es inconstitucional.

«El ámbito material más directamente implicado en los Planes de Pensiones, por su finalidad y estructura, es, por un lado, el mercantil, respecto del cual el Estado es competente para establecer su legislación (art. 149.1.6), en cuanto se trata de regular el contenido obligacional de un contrato de esa naturaleza, y, por el otro, el de los seguros, en relación con el cual, como ocurre con el crédito y la banca, al Estado se le atribuye el establecimiento de las bases para su ordenación (art. 149.1.11), desde la perspectiva de la intervención administrativa, con sus garantías y cautelas, en este sector económico (STC 330/1994, f.j. 2. ${ }^{\circ}$ ), mientras que las Comunidades Autónomas lo son para el desarrollo legislativo y la ejecución de tales normas básicas (arts. 11.2.a EAPV y 10.1.4 EAC). A ese esquema de distribución de competencias sólo escapan subsectores concretos por la concurrencia de otros títulos competenciales específicos, los cuales, por su propia especialidad, no permiten una interpretación expansiva con la inclusión, en este caso, de los Planes y Fondos de Pensiones en la noción de "mutualidades no integradas en la Seguridad Social". Además, esos subsectores caen, también, como ya ha quedado dicho, bajo la órbita de la competencia estatal $e x$ art. 149.1.11 CE en cuanto aquellas entidades realicen actividades que, como la aseguradora, debe regular el Estado mediante el establecimiento de sus bases (SSTC 86/1989 ff.jj. 5. ${ }^{\circ}$ y 7. ${ }^{\circ}$; 35/1992, f.j. 2. ${ }^{\circ}$; y 220/1992, f.j. 3. ${ }^{\circ}$ ).

Así pues, el canon que hemos de utilizar para la controversia competencial que, parcialmente, subyace a la interposición de los presentes recursos de inconstitucionalidad es el antedicho - seguros-, que no se refiere a una determinada modalidad contractual sino "a la ordenación administrativa de un sector económico como lo son también la banca y el crédito que en la misma regla se mencionan", donde están incluidas actividades distintas de la estricta formalización de contratos de seguros (STC 330/1994, f.j. 2. ${ }^{\circ}$ ), y donde también, como ha quedado dicho, está presente la dialéctica bases-desarrollo legislativo. Ésta, para determinar cuáles aspectos sean básicos y cuáles propios de una legislación de desarrollo, exige la ponderación de diversos elementos como la natura- 
leza de la materia o la mayor o menor necesidad de una regulación uniforme de sus diversas facetas en todo el territorio nacional (STC 86/1989, f.j. 2. ${ }^{\circ}$ ), sin o]vidar la clara dimensión financiera que tienen los Planes [art. 149.1.13 (SSTC 86/1989, (f.j. 3. ${ }^{\circ}$, y 330/1994, f.j. 2. ${ }^{\circ}$ )], más visible aún, como se comprobará, en el caso de los Fondos de Pensiones, sin los cuales los Planes carecerían de sentido y consistencia» (vid. f.j. 7).

«No pueden dejar de considerarse básicas las definiciones genéricas de los diversos niveles de infracciones, contenidas en los apartados 3, 4 y 5 del art. 25 de la Ley, en cuanto señalan los elementos centrales de graduación de las conductas típicas que a continuación se describen. De forma igual cabe concluir en relación con el listado de infracciones de los mismos apartados 3 a 5 del artículo 25, puesto que todos ellos definen los tipos en relación con obligaciones nacidas del régimen jurídico de los Planes y Fondos de Pensiones que, por incumbir a aspectos esenciales del régimen organizativo de unos y otros [apartados a) del núm. 3 y f) del núm. 4 del art. 25], o del sistema de garantías previsto para asegurar su solvencia y estabilidad financiera, tanto por lo que hace a los derechos y obligaciones de alcance interno entre los Fondos y sus entidades gestoras o depositarias (apartados b) y c) del art. 25.3; apartados a), b), c), d), e), g), h) e i) del art. 25.4; apartados b), c), d), e), f), g) e i) del art. 25.5], como por lo que hace a las obligaciones impuestas para facilitar el control de gestión por parte de los organismos competentes [apartados j) y k) del art. 25.4 y apartado h) del art. 25.5], afectan, en su totalidad, a aspectos básicos de la materia regulada, en los términos en que se ha tenido ocasión de expresar en los fundamentos anteriores.

Sólo cabe hablar de una excepción, dado el carácter excesivamente genérico y residual del precepto [art. $25.3 \mathrm{~d}$ )], que incluye en el tipo, teóricamente, tanto a obligaciones que sí son básicas como a otras que no lo son y que pueden imponerse en el ejercicio de la potestad reglamentaria del Gobierno. No pudiendo saberse si son básicas las normas o disposiciones, obligaciones o prohibiciones a que se refiere, no es admisible en el juego bases-desarrollo donde nos movemos una tipificación genérica y abstracta como la contemplada, que, además de colisionar con el art. 25.1 CE, en la medida en que habilita o remite al Reglamento para la configuración ex novo de obligaciones o prohibiciones cuya contravención da origen a una infracción sancionable (STC 341/1993, f.j. 10), no permite el desarrollo normativo por parte de las Comunidades Autónomas» (vid. f.j. 15).

Fallo: 1..$^{\circ}$ Declarar que el art. 25.3 d) de la Ley 8/1987, de 8 de junio, de Regulación de los Planes y Fondos de Pensiones, es inconstitucional y, por tanto, nulo. 
2. $\quad$ Desestimar los recursos en todo lo demás.

(Sentencia n. ${ }^{\circ}$ 206/1997, de 27 de noviembre. Pleno. BOE 30 de diciembre de 1997. R. de Mendizábal Allende. Votos particulares formulados, el primero de ellos, por P. Cruz Villalón, al que se adhiere C. Viver Pi-Sunyer, y el segundo, por T. S. Vives Antón, al que se adhiere P. García Manzano).

\section{ENSEÑANZA}

1. Conflicto positivo de competencia núm. 1524/1988 promovido por el Consejo de Gobierno de la Comunidad Autónoma de las Islas Baleares, en relación con los dos últimos párrafos de la cláusula cuarta.3 del Convenio entre el Ministerio de Educación y Ciencia y el de Defensa, sobre régimen, promoción y funcionamiento de centros de enseñanza, aprobado por Real Decreto 295/1988, de 25 de marzo, relativos a la enseñanza en tales centros de la lengua propia de la Comunidad, así como de la eventual exención de tal ensenanza. El TC declara que la competencia controvertida corresponde a la Comunidad Autónoma de las Islas Baleares.

«El presente conflicto positivo de competencia se centra en el Convenio suscrito entre los Ministerios de Educación y Ciencia y de Defensa, sobre régimen, promoción y funcionamiento de Centros de Enseñanza, que fue aprobado por el Real Decreto 295/1988, de 25 de marzo. Tal y como se indica en su Preámbulo, este Convenio venía a sustituir a otro anterior, suscrito el año 1978, cuya razón de ser residía en "la necesidad de que el personal de las Fuerzas Armadas contase con Centros escolares suficientes, debidamente coordinados, para que los frecuentes traslados de residencia a que se ve sometido dicho personal no perjudicase la trayectoria educativa de sus hijos". Y, persistiendo tal circunstancia, fue, precisamente, la necesidad de acomodar lo dispuesto en aquel primer Convenio al espíritu de la Ley Orgánica $8 / 1985$, reguladora del derecho a la educación (en adelante, LODE), la que impulsó el establecimiento del que ahora se impugna, según asegura el referido Preámbulo del Real Decreto 295/1988.

Más concretamente, el controvertido Convenio, cuyo ámbito de aplicación — cumple señalar - se ciñe exclusivamente a determinados Centros docentes cuyo titular es el Ministerio de Defensa, ha sido impugnado porque en los últimos incisos de la cláusula cuarta. 3 se establece lo siguiente: "Por lo que respecta a la enseñanza de la lengua propia de la Comunidad, tendrá carácter obligatorio con la consideración de asignatura con los mismos efectos académicos y administrativos que las restantes materias o áreas que constituyan el Plan de estudios. No obstante, el Ministerio de Educación y Ciencia podrá con- 
ceder la exención de cursar la enseñanza de la lengua propia de la Comunidad en los casos y mediante el procedimiento que se determine".

A juicio de la representación de la Comunidad Autónoma de las Islas Baleares, acordar sobre la enseñanza de la lengua catalana, propia de las Islas Baleares, así como eximir de la enseñanza de la misma, es una atribución que sólo corresponde a la Comunidad Autónoma, según se desprende de los arts. 3.2 y 148.1.17.a CE, y de las competencias que en punto a la materia linguística le reconoce su Estatuto de Autonomía, especialmente su art. 14, en virtud del cual:

"La Comunidad Autónoma tiene competencia exclusiva, en armonía con los planes de estudios estatales, para la enseñanza de la lengua catalana, propia de las Islas Baleares, de acuerdo con la tradición literaria autóctona. Su normalización será un objetivo de los poderes públicos de la Comunidad Autónoma. Las modalidades insulares del catalán serán objeto de estudio y protección, sin perjuicio de la unidad del idioma".

Frente a esta posición, entiende el Abogado del Estado que la capacidad debatida encuentra, en última instancia, un suficiente anclaje constitucional tanto en la competencia exclusiva que el Estado ostenta sobre "Defensa y Fuerzas Armadas" (art. 149.1.4.a), como en las competencias estatales de homologación del sistema educativo y desarrollo del derecho fundamental a la educación que la Constitución igualmente le atribuye» (vid. f.j. 1).

«Apunta el Abogado del Estado que de la mencionada Disposición final segunda de la LODE - en conexión con la primera - se desprende con claridad la facultad estatal para regular enteramente la enseñanza en los Centros objeto del Convenio; atribución específica frente a la cual no basta la invocación general de la competencia autonómica para normar la cooficialidad de la lengua propia. Por contra, la representación de la Comunidad Autónoma mantiene que la habilitación aludida debe entenderse necesariamente en el ámbito de las competencias educativas del Estado, sin que permita fundamentar la invasión de su competencia exclusiva en orden a la enseñanza de su lengua propia.

Pues bien, al acometer la delimitación del alcance de esta habilitación que autoriza al Gobierno a introducir modificaciones en el régimen educativo general, ha de partirse de que la misma en el marco del art. 149.1.30.a CE, debe necesariamente incardinarse a "garantizar el cumplimiento de las obligaciones de los poderes públicos" respecto del derecho a la educación. Los límites y las posibilidades de tal habilitación deben fijarse, por consiguiente, atendiendo estrictamente a su vinculación con dicha finalidad. 
Como se indica en el Preámbulo del Real Decreto 295/1988, la pretensión del Convenio en su conjunto es asegurar el más adecuado disfrute del derecho a la educación de los hijos del personal militar, cuyo normal desenvolvimiento puede verse trastornado con motivo de unos traslados de residencia que, en función de las necesidades de organización de la defensa nacional, pueden llegar a ser harto frecuentes en el seno de las Fuerzas Armadas. Se orienta claramente a dicho objetivo, sin que el resultado alcanzado pueda considerarse excesivo en atención a esa finalidad, la medida prevista en el apartado primero de la Cláusula Cuarta, según la cual tienen derecho preferente a ser admitidos en los Centros contemplados en el Convenio "los hijos del personal militar que tenga su destino en la localidad, o establecida en ella su residencia familiar", o que, en el apartado 3 de la misma Cláusula Cuarta, segundo inciso, se prevea la utilización del castellano como lengua docente.

Sucede, sin embargo, que la cuestión que aquí se debate no versa sobre la enseñanza "en" catalán, lengua propia de la Comunidad Autónoma de las Islas Baleares, sino sobre la enseñanza "de" dicha lengua como asignatura. Es decir, el conflicto afecta a una concreta materia respecto de la cual el Estatuto - de acuerdo con el art. 148.1.17.a CE - ha previsto expresamente la competencia autonómica exclusiva: "La Comunidad Autónoma —dice el art. 14 del Estatuto, que ahora resulta pertinente reiterar- tiene competencia exclusiva, en armonía con los planes de estudios estatales, para la enseñanza de la lengua catalana...".

El Consejo de Gobierno balear, en definitiva, esgrime un título competencial específico, que, además, como vimos supra en el fundamento jurídico $2 .^{\circ}$, fue utilizado en la Ley $3 / 1986$, de Normalización Lingüística, para atribuir precisamente a sus órganos competentes la facultad de decidir acerca de la enseñanza del catalán, lengua propia de las Islas Baleares así como de la eventual exención de tal enseñanza. Planteado de este modo el asunto, se llega a la conclusión de que las controvertidas disposiciones estatales entrañan una injerencia ilegítima en el ámbito competencial acotado por el Estatuto de Autonomía para las Islas Baleares» (f.j. 5).

Fallo: Declarar que la competencia controvertida corresponde a la Comunidad Autónoma de las Islas Baleares.

(Sentencia n. ${ }^{\circ}$ 134/1997, de 17 de julio. Pleno. BOE 6 de agosto de 1997. M. Jiménez de Parga y Cabrera).

\section{PROPIEDAD INTELECTUAL}

1. Recursos de inconstitucionalidad acumulados núms. 256 y 264/1988, promovidos, respectivamente, por el Consejo Ejecutivo de la Generalidad de 
Cataluña y por el Gobierno Vasco, en relación con diversos preceptos de la Ley 22/1987, de 11 de noviembre, de Propiedad Intelectual. El TC estima parcialmente los recursos y declara contrarios al orden constitucional de competencias, en los términos expresados en el fundamento jurídico 11 , los apartados $1 .^{\circ}$ (excepto el inciso final ) y $3 .^{\circ}$ del art. 144 del Texto Refundido de la Ley de Propiedad Intelectual, aprobado por Real Decreto Legislativo 1/1996, de 12 abril, cuyas facultades corresponden dentro de sus respectivos territorios a las Comunidades Autónomas recurrentes.

«El art. 144 de la LPI regula una serie de medidas de intervención y control administrativo sobre las entidades de gestión de los derechos de propiedad intelectual, todas las cuales reserva al Ministerio de Cultura. En su apartado primero le atribuye la facultad de vigilancia sobre el cumplimiento de las obligaciones y requisitos legalmente establecidos para aquéllas, previendo que a tal efecto el Ministerio de Cultura podrá exigir de estas entidades cualquier tipo de información, ordenar inspecciones y auditorías y designar un representante que asista con voz pero sin voto a sus Asambleas Generales, Consejos de Administración u órganos análogos. El apartado segundo dispone que las modificaciones de los Estatutos de las entidades de gestión deberán someterse a la aprobación del Ministerio de Cultura, la cual se entenderá concedida, si no se notifica resolución en contrario, en el plazo de tres meses desde su presentación. Y, finalmente, el apartado tercero impone a las entidades de gestión la obligación de notificar al Ministerio de Cultura los nombramientos y ceses de sus administradores y apoderados, las tarifas generales y sus modificaciones, los contratos generales celebrados con asociaciones de usuarios y los concertados con entidades extranjeras, así como los documentos mencionados en el art. 141 de la LPI, esto es, el balance y la documentación contable, la memoria de actividades y el dictamen de las auditorías o censura de cuentas. La distinta naturaleza de las intervenciones administrativas establecidas en este precepto, no permite un tratamiento unitario de su impugnación y, aunque ésta lo sea, conviene distinguir:

A) La prevista en el apartado segundo, del art. 144 que somete las modificaciones de los estatutos de las Entidades de gestión a la aprobación del Ministerio de Cultura, está estrecha e íntimamente vinculada a las facultades de autorización que a aquél se le atribuyen en el art. 132 de la LPI. En efecto, una de las condiciones a las que el art. 133.1, a) subordina la concesión de la autorización para el acceso a la cualidad de Entidad de gestión, es la de que los estatutos de la entidad solicitante cumplan los requisitos establecidos en el Título IV del Libro III de la LPI (arts. 132, 136, 137, 138, 139 y 141). Cumplimiento que ha de mantenerse por las Entidades de gestión en los supuestos en que procedan a la modificación de sus estatutos. Correspondiendo al Ministerio de Cultura previa verificación de que los mismos cumplen los requisitos exigidos, 
la autorización que, como hemos visto, no resulta viciada de incompetencia, es a él a quien ha de corresponder también, dada la estrecha vinculación que con aquéllas presenta, la facultad de aprobar las modificaciones estatutarias de las Entidades de gestión. Precisamente la Generalidad de Cataluña pretende esta competencia, en razón a que debe ser atribuida a la Administración autorizante. Si ésta, por lo razonado anteriormente, corresponde al Estado, decae la base de esta pretensión. Sería contradictorio que una de las condiciones tenidas en cuenta para otorgar la autorización pudiera ser modificada por quien no es competente para su otorgamiento. Procede, por tanto, desestimar la impugnación de las recurrentes contra el ap. 2 del art. 144 de la Ley de Propiedad Intelectual.

B) A distinta conclusión ha de llegarse, respecto de las facultades de intervención administrativa que enuncian los apartados primero y tercero del art. 144 de la LPI que tienen por objeto, la inspección, la vigilancia y el control de las Entidades de gestión. Su atribución al Ministerio de Cultura debe considerarse contraria al orden competencial que en materia de propiedad intelectual resulta de los arts. 149.1.9.a de la CE, 11.3 del EAC y 12.4 del EAPV, pues se trata de funciones sobre actividades regladas que son por ello típicamente ejecutivas. Su reserva a la Administración del Estado no aparece justificada por la necesidad de mantener unos criterios generales y uniformes en su ejercicio, configurándose la intervención de la correspondiente autoridad autonómica como garantía suficiente para la salvaguardia de los intereses afectados y la consecución de los objetivos pretendidos. No concurre en este caso, como sí acontece en relación con los arts. 132 y 134 de la LPI, la necesidad de que las condiciones para acceder al status de Entidad de gestión sean aplicadas de forma unitaria en todo el territorio nacional, ni circunstancia excepcional alguna que justifique la atribución al Estado de estas facultades de ejecución y se excluya a las Comunidades Autónomas del normal ejercicio de las competencias asumidas en sus respectivos Estatutos.

El Estado, que ostenta todas las facultades normativas en esta materia, a través de ellas puede garantizar que la forma en que las Comunidades Autónomas realicen la ejecución de las mismas mediante las funciones de control, inspección y vigilancia sobre las Entidades de gestión no redunde en manifiestas e irrazonables diferencias (STC 100/1991, f.j. 3), así como, en razón de su competencia normativa, articular los mecanismos de colaboración, coordinación e información recíproca necesarios (SSTC 100/1991, f.j. 5; 236/1991, f.j. 6; 243/1994, f.j. 7), al objeto de que a la Administración estatal le sean suministrados y disponga de los datos que sean precisos en cuanto titular de la facultad de revocar la autorización, a cuyo ejercicio están ordenadas las actividades de inspección, vigilancia y control recogidas en los apartados primero y tercero del art. 144 de la Ley de Propiedad Intelectual. 
A esta materia típicamente de ejecución sí es aplicable la jurisprudencia anteriormente expuesta, según la cual el alcance territorial supraautonómico de las actividades de las Entidades de gestión no permite desplazar, sin más, la titularidad de las competencias controvertidas al Estado. Porque no se trata de funciones que fragmenten el régimen unitario establecido por el legislador, sino de actividades tendentes a que la normativa que regula la actuación de las Entidades de gestión la cumplan con sujeción a la Ley que las crea.

Por tanto, el ap. 1 (salvo el inciso inicial que dice "corresponde al Ministerio de Cultura, además de la facultad de otorgar o revocar la autorización regulada en los arts. 133 y 134") y el ap. 3 del art. 144 de la LPI, en virtud de la reserva de facultades al Estado que en ellos se efectúa, invaden la competencia de ejecución atribuida en materia de propiedad intelectual a las Comunidades Autónomas de Cataluña y del País Vasco por los arts. 11.3 y 12.4 de sus respectivos Estatutos de Autonomía y, en consecuencia, tales facultades corresponden a las Comunidades recurrentes» (f.j. 11).

Fallo: $10^{\circ}$ Declarar que la impugnación de los arts. 129 y 130.5 de la Ley 22/1987, de 11 de noviembre, de Propiedad Intelectual, formulada en el recurso interpuesto por el Gobierno Vasco, ha quedado sin objeto por derogiluión sobrevenida de los mismos.

2. Estimar parcialmente los recursos de inconstitucionalidad interpuestos por el Consejo Ejecutivo de la Generalidad de Cataluña y el Gobierno Vasco contra determinados artículos de la Ley 22/1987, de 11 de noviembre, de Propiedad Intelectual, y, en consecuencia, declarar contrarios al orden constitucional de competencias, en los términos expresados en el último párrafo del fundamento jurídico undécimo de esta sentencia, los aps. $1 .^{\circ}$ (excepto el inciso inicial) y $3 .^{\circ}$ del art. 144 de la citada Ley y, por tanto, su actual reproducción por los aps. $1 .^{\circ}$ y $3 .^{\circ}$ del art. 154 del Texto Refundido de la Ley de Propiedad Intelectual, aprobado por Real Decreto Legislativo 1/1996, de 12 de abril, cuyas facultades corresponden dentro de sus respectivos territorios a las Comunidades Autónomas recurrentes.

\section{Desestimar los recursos en todo lo demás.}

(Sentencia n. ${ }^{\circ}$ 196/1997, de 13 de noviembre. Pleno. BOE 12 de diciembre de 1997. F. García-Mon y González Regueral. Votos particulares formulados, el primero por T. S. Vives Antón, y el segundo, por C. Viver Pi-Sunyer, al que se adhiere P. Cruz Villalón). 